\title{
Modelo conceptual del sistema acuífero de Enchereda (La Gomera, Islas Canarias): contribuciones a otras islas volcánicas
}

\author{
Conceptual model of Enchereda aquifer system (La Gomera, Canary \\ Islands): contributions to other volcanic islands
}

\author{
T. Izquierdo¹, R. Herrera ${ }^{1}$, Á. Márquez ${ }^{1}$
}

\begin{abstract}
RESUMEN
La elaboración de modelos conceptuales en acuíferos de islas volcánicas presenta una elevada dificultad debido a la complejidad estructural de los materiales volcánicos, incrementada por 1) los procesos de destrucción (p. ej., deslizamientos de flanco) y 2) la intrusión de diques, que pueden actuar como zonas de flujo preferente o sobreelevando el agua localmente. En algunos casos, la falta de información hidrogeológica en el interior de las islas dificulta aún más la caracterización del funcionamiento de los acuíferos en estas zonas. En este trabajo se evalúa el papel de los diques y de los depósitos volcanoclásticos en el flujo regional de la zona de Enchereda (La Gomera, Islas Canarias) y en particular, en su zona más elevada. En esta zona se definen tres unidades hidroestratigráficas: los Basaltos Antiguos Inferiores moderadamente permeables; a techo las Brechas Volcánicas de baja permeabilidad; y por encima los Basaltos Antiguos Superiores, permeables. Las brechas parecen actuar como límite inferior impermeable del acuífero y en su reconstrucción se observa que presentan una geometría coherente con un buzamiento general hacia el ESE de aproximadamente $13^{\circ}$, condicionando el flujo regional del agua en el acuífero. La cartografía de los diques mediante fotografía y ortofotografía aérea así como en campo y en el interior de la galería de Ipalán, ha permitido identificar cuatro familias de diques. Los diques NO-SE son los más abundantes, con una densidad máxima de más de 10 diques $/ 100 \mathrm{~m}$, similar a otras zonas de rift en volcanes oceánicos. Estos diques son paralelos al flujo regional del agua en el acuífero y actuarían por tanto como zonas de flujo preferente, mientras que los diques con direcciones N-S y NE-SO sobreelevarían el nivel piezométrico, generando una superficie escalonada, al ser perpendiculares a la dirección flujo. Por último, los diques E-O parecen influir en menor medida en el acuífero. Nuestros resultados plantean la necesidad de reevaluar principalmente la influencia de los diques en el flujo regional de acuíferos en otras islas volcánicas en las que su papel se ha minimizado, ya que la superposición de diferentes familias de diques puede condicionar el movimiento del agua en el acuífero.
\end{abstract}

Palabras clave: modelo conceptual, hidrogeología, acuífero volcánico, La Gomera, Islas Canarias.

\begin{abstract}
Hydrogeological conceptual models are difficult to develop in volcanic islands due to scarce hydrogeologic information in the inner parts of the islands and the complex structure of volcanic materials. This complexity is increased by 1) destruction processes (for example, flank collapse) and 2) dike intrusion. Dikes can both channel groundwater flow parallel to their general trend or act as barriers impounding it. In this paper we evaluate the role of dikes and volcanoclastic deposits in Enchereda aquifer system (La Gomera, Canary Islands) regional flow and particularly, in its higher area. In this aquifer system three hydrostratigraphic units can be identified: the Lower Old Basalts, with low permeability; the Volcanic Breccia, impermeable; and the Upper Old Basalts, permeable. The breccia seems to act as the impermeable limit of the aquifer and the reconstruction of its geometry shows a coherent
\end{abstract}

\footnotetext{
1 Grupo de Geología. Universidad Rey Juan Carlos, Móstoles (Madrid) 28933. Email: tatiana.izquierdo @urjc.es
} 


\begin{abstract}
surface dipping about $13^{\circ}$ towards the ESE what determines the regional flow in the aquifer. After dike mapping using aerial photograph and orthophotograph as well as mapping in the field and inside Ipalán water tunnel, four dike swarms have been identified. NW-SE dikes are the most frequent ones, and show a maximum density of more than 10 dikes $/ 100 \mathrm{~m}$, similar to rift zones in volcanic islands. These dikes are parallel to the regional flow and channel water flow whereas the N-S and NE-SW swarms impound groundwater rising the water table level forming a stepped surface as they are perpendicular to the regional flow. Lastly, W-E dikes seem to have little influence on the aquifer. Our results show the need of a re-evaluation of the role of dikes in the regional flow in other volcanic island aquifers in which their influence have been minimized as overlapping of different dike swarms can condition regional flow in the aquifer.
\end{abstract}

Key words: conceptual model, hydrogeology, volcanic aquifer, La Gomera, Canary Islands.

\section{Introducción}

Los modelos conceptuales de acuíferos en islas volcánicas son aún controvertidos en numerosas regiones del mundo, como por ejemplo, la Isla de Reunión (Join et al., 2005) o la isla de Pascua (Herrera \& Custodio, 2008) debido a dos factores principales: la falta de información hidrogeológica en el interior de estas islas por la escasez de captaciones lejos de la costa, y la complejidad estructural de las islas volcánicas. En las islas volcánicas aparecen materiales con propiedades hidráulicas muy variadas, como coladas de lava, materiales piroclásticos, volcanoclásticos o sedimentarios. Además, los materiales volcánicos pueden presentar permeabilidades muy variadas, con valores muy altos y anisótropos en formaciones jóvenes (debido a las partes más escoriáceas y al diaclasado de las coladas de lava), que se reducen drásticamente con el paso del tiempo por alteración, compactación y mineralización secundaria (Custodio, 1978). Asimismo, la intrusión de diques juega un papel clave, en general reduciendo los valores de permeabilidad primaria en función del número, volumen, geometría y densidad de la red diques (Takasaki \& Mink, 1985). La variabilidad en la longitud, espesor y características (p.ej., diaclasado) de los diques hace que sea difícil evaluar a priori su papel en los modelos de flujo subterráneo, pudiendo actuar como zonas de flujo preferente o impidiendo el flujo y obligando a almacenar el agua localmente al ser más impermeables que la roca caja (Custodio, 1978). La alternancia de episodios constructivos y destructivos (p.ej., deslizamientos) en los edificios volcánicos insulares provoca que la geometría de todos estos materiales pueda ser muy compleja, por lo que la falta de datos del subsuelo en zonas internas de las islas dificulta enormemente la construcción de modelos conceptuales de sus acuíferos.
En las Islas Canarias existe una inusual cantidad de obras hidráulicas (pozos de gran diámetro, sondeos y galerías) lejos de las zonas costeras, que permiten un conocimiento excepcional de su hidrogeología, en comparación con otros archipiélagos volcánicos, como las islas Hawai. En los modelos hidrogeológicos de Hawai se diferencia habitualmente entre acuíferos basales, con conexión hidráulica con el agua de mar, y acuíferos elevados sin conexión en los que el agua se encuentra en las coladas basálticas quasi-atrapada entre diques verticales (Lau \& Mink, 2006). Para Canarias, Custodio $(1978 ; 2004 ; 2007)$ definió un modelo conceptual en el que algunas islas cuentan con un núcleo de baja permeabilidad cubierto por sucesivos edificios volcánicos más recientes. Algunos estudios en galerías de extracción de agua en Tenerife han resaltado la importancia de los diques en los modelos hidrogeológicos (por ejemplo, Niñerola et al., 1974; Navarro \& Farrujia, 1989), por lo que en la actualidad el papel de los diques en los modelos conceptuales de Canarias se considera variable (Custodio \& Cabrera, 2008). Además, en Canarias se ha comprobado la importancia hidrogeológica de los grandes deslizamientos de flanco. El relleno de las depresiones generadas en estos deslizamientos por materiales permeables que se apoyan directamente sobre las brechas de deslizamiento, de matriz muy arcillosa, los convierten en importantes acuíferos (p. ej., el acuífero de Icod-Cañadas en Tenerife; Navarro \& Farrujia, 1989).

En este trabajo se analiza la zona de Enchereda (La Gomera, Islas Canarias; fig. 1) y en particular su sector más elevado, escogida por su configuración geológica y topográfica y por la existencia de una serie de obras de extracción de aguas subterráneas a cotas elevadas. La zona se encuentra situada en el este de la isla y abarca un área de $38,8 \mathrm{~km}^{2}$ (el $10 \%$ de la superficie de la isla), desde la costa hasta 


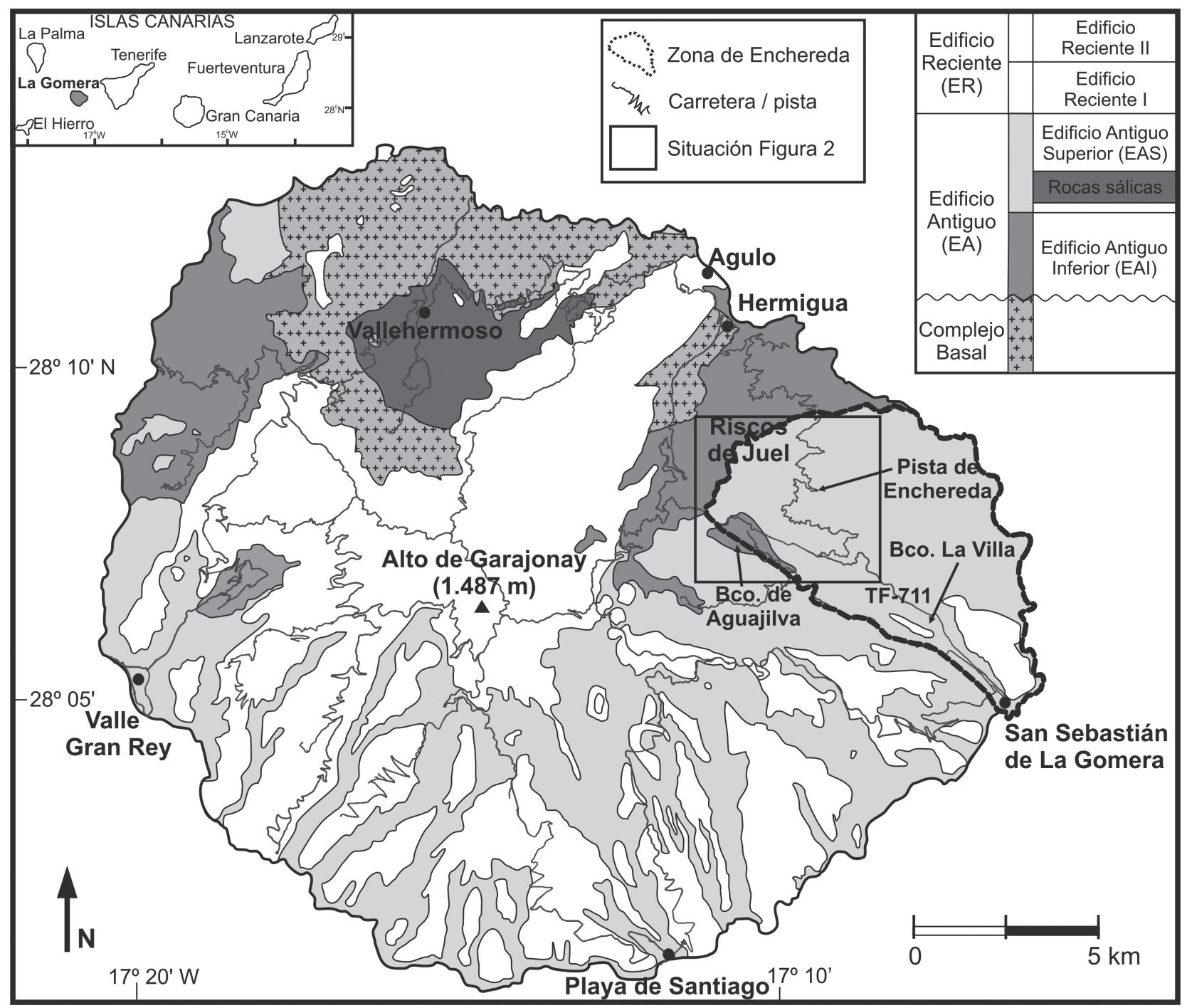

Fig. 1.-Localización geográfica y mapa geológico simplificado de la isla de La Gomera (modificado de Ancochea et al., 2006) en el que se marca la zona de estudio y la situación de la fig. 2.

una altura máxima de $1.063 \mathrm{msnm}$ en los Riscos de Juel (fig. 1). El agua subterránea supone el $80 \%$ de los recursos hídricos de La Gomera (Soler et al., 2002), y en el caso de Enchereda las extracciones abastecen a los municipios de San Sebastián, Hermigua y Agulo (8.744, 2.178 y 1.187 habitantes respectivamente; www.ine.es) y se realizan a través de seis sondeos (fig. 2); cinco a lo largo de la pista de Enchereda (Ventana del Diablo, Enchereda I, Enchereda II, Los Campos y Juel, 540 - 675 msnm) y uno en la carretera TF-711 de San Sebastián a Hermigua (Cañada Hurona, $341 \mathrm{msnm}$ ). El volumen de agua extraído es de aproximadamente 1 $\mathrm{Hm}^{3}$ al año. Además, en la zona se ha finalizado la construcción de la galería de Ipalán en el Barranco de La Villa (a 200 msnm; fig. 2) que complementará las extracciones de los sondeos para abastecimiento. Por último, existen dos sondeos inactivos en la pista de Enchereda, Los Campos II y El Helechal (635 y $687 \mathrm{msnm}$ respectivamente) de los cuales se dispone de la descripción de la columna litológica.

El objetivo principal de este trabajo es evaluar el papel de los diques y de los depósitos volcanoclásticos, como los generados en los deslizamientos de flanco, en el almacenamiento de agua subterránea en acuíferos volcánicos, mediante el estudio de una zona representativa y con disponibilidad de 


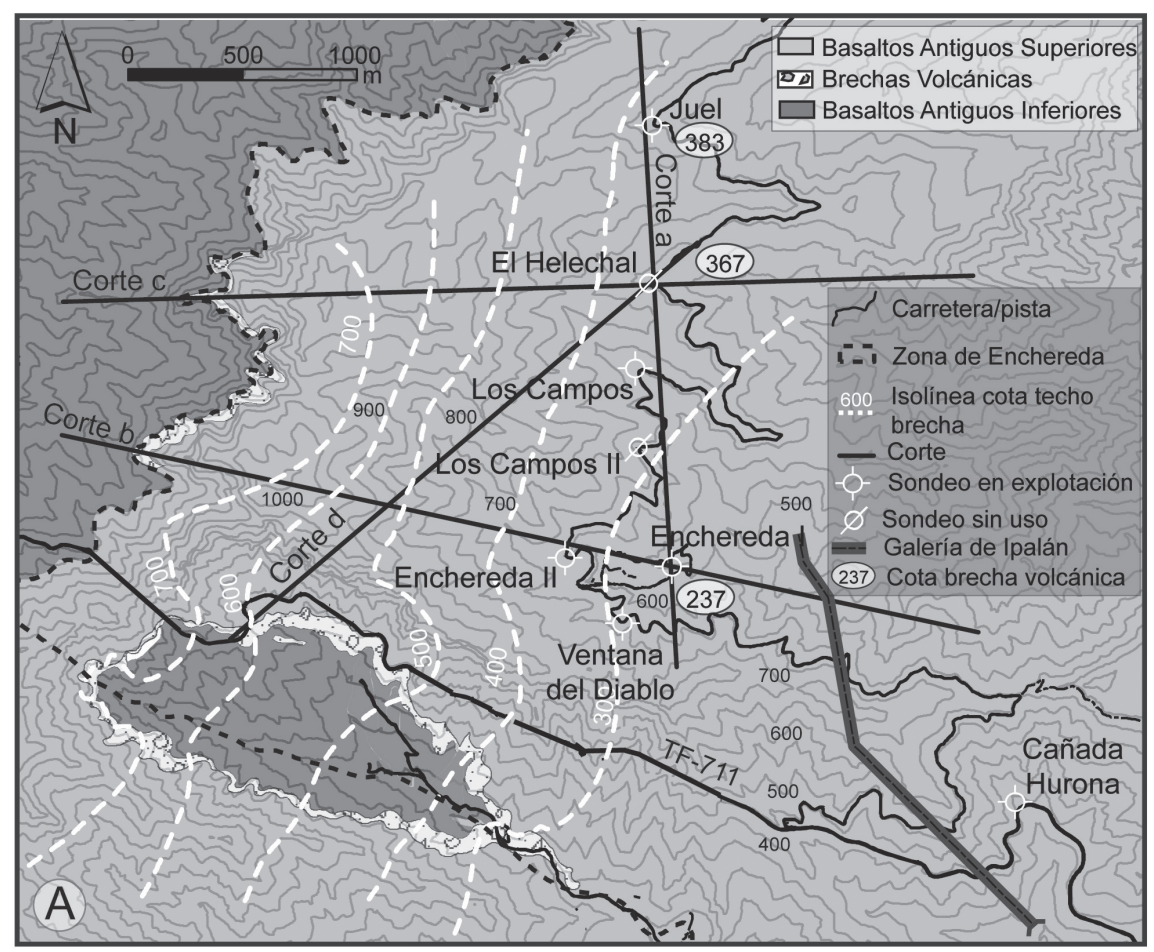

(B)
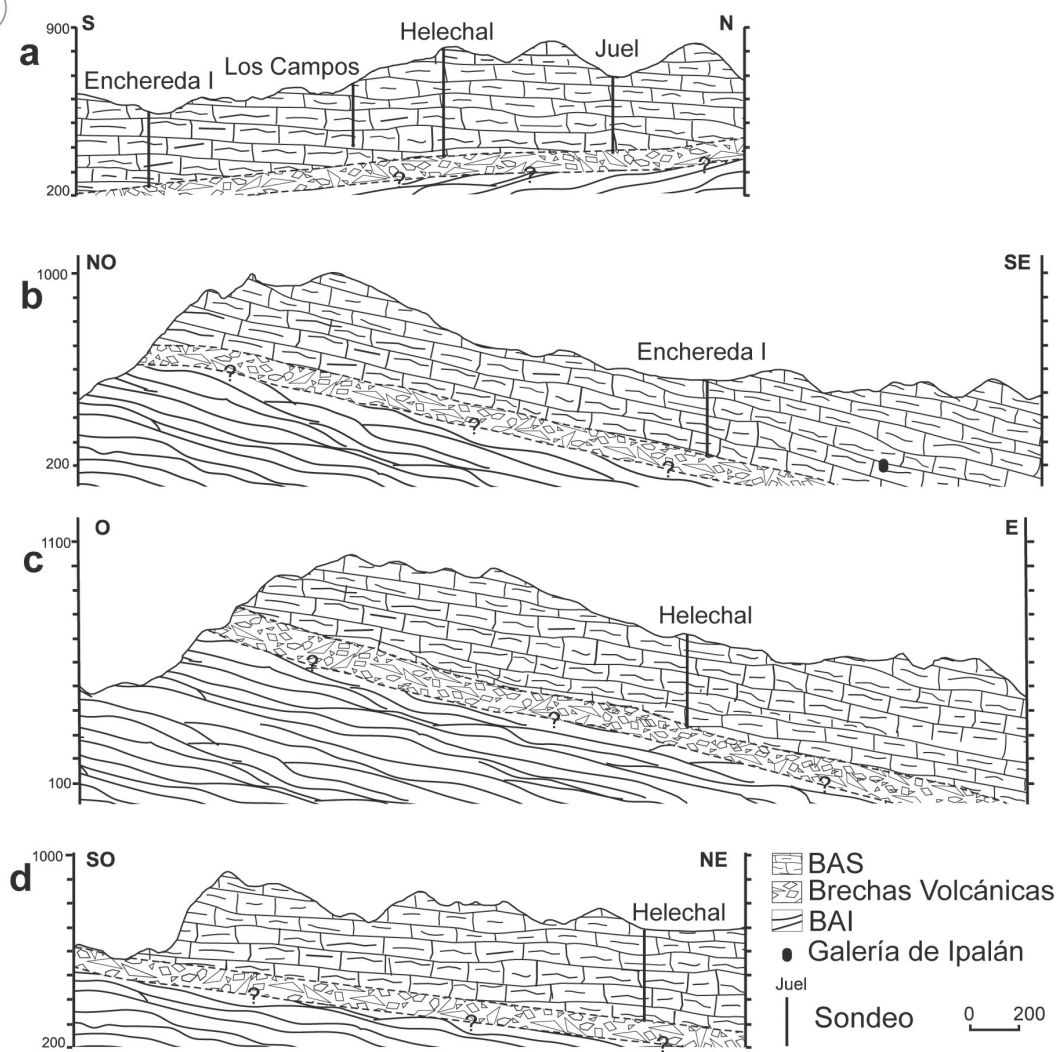

Fig. 2.-A) Mapa geológico de los afloramientos de las Brechas Volcánicas en el que se muestra la reconstrucción de las isolíneas de profundidad del techo de las Brechas Volcánicas así como las obras de extracción de agua en la zona y la situación de los cortes; B) Cortes geológicos de la zona alta de Enchereda en los que se reconstruye la geometría del acuífero. 
Tabla 1..-Volcanoestratigrafía de la isla de La Gomera (Herrera, 2008) y correlación con las unidades hidroestratigráficas estudiadas en este trabajo

\begin{tabular}{|c|c|c|c|c|c|c|}
\hline \multicolumn{5}{|c|}{ Volcanoestratigrafía (Herrera, 2008) } & Unidad hidroestratigráfica & Comportamiento \\
\hline $\begin{array}{c}2 \mathrm{Ma} \\
\text { Edificio }\end{array}$ & \multicolumn{2}{|c|}{ Edificio Reciente II } & $\begin{array}{c}\text { Unidad } \\
\text { Traquítica y } \\
\text { Domos Sálicos }\end{array}$ & $\begin{array}{c}\text { Basaltos } \\
\text { Recientes II }\end{array}$ & $* *$ & 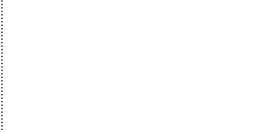 \\
\hline 5,9 Ma & \multicolumn{2}{|c|}{ Edificio Reciente I } & \multicolumn{2}{|c|}{ Basaltos Recientes I } & & \\
\hline $6,2 M a$ & \multirow{2}{*}{$\begin{array}{l}\text { Edificio } \\
\text { Antiguo } \\
\text { Superior } \\
(8,6-6,2 \mathrm{Ma})\end{array}$} & $\begin{array}{l}\text { Edificio Antiguo } \\
\text { Superior II }\end{array}$ & $\begin{array}{l}\text { Rocas Sálicas } \\
\text { de Vallehermoso }\end{array}$ & $\begin{array}{c}\text { Basaltos } \\
\text { Antiguos } \\
\text { Superiores II }\end{array}$ & \multirow{2}{*}{ Acuífero } & \multirow{2}{*}{ Permeable } \\
\hline \multirow{2}{*}{$\begin{array}{l}\text { Edificio } \\
\text { Antiguo }\end{array}$} & & $\begin{array}{l}\text { Edificio Antiguo } \\
\text { Superior I }\end{array}$ & $\begin{array}{l}\text { Rocas Sálicas } \\
\text { del Este }\end{array}$ & $\begin{array}{c}\text { Basaltos } \\
\text { Antiguos } \\
\text { Superiores I }\end{array}$ & & \\
\hline & \multirow{2}{*}{\multicolumn{2}{|c|}{$\begin{array}{l}\text { Edificio Antiguo Inferior } \\
\quad(10,5-8.7 \mathrm{Ma})\end{array}$}} & \multicolumn{2}{|c|}{ Brechas Volcánicas } & Límite impermeable & Baja permeabilidad \\
\hline $10,5 \mathrm{Ma}$ & & & Basaltos Antig & los Inferiores & $\begin{array}{l}\text { Potencial acuífero } \\
\text { sin conexión hidráulica } \\
\text { con el acuífero superior }\end{array}$ & $\begin{array}{l}\text { Moderadamente } \\
\text { permeable } \\
\text { (para Enchereda) }\end{array}$ \\
\hline$>12 \mathrm{Ma})$ & \multicolumn{4}{|c|}{ Complejo Basal y Edificio Submarino } & $\begin{array}{l}\text { Zócalo impermeable } \\
\text { de la isla }(*)\end{array}$ & Impermeable \\
\hline
\end{tabular}

* Se desconoce si está presente en profundidad en la zona de Enchereda; ${ }^{* *}$ No aparece en la zona de Enchereda.

datos de campo y de captaciones. Para ello se han caracterizado en la zona de Enchereda mediante trabajos de campo y de gabinete: 1) las unidades hidroestratigráficas; 2) la geometría del acuífero; 3) la red de diques; y 4) la posición de la superficie piezométrica.

\section{Contexto geológico e hidrogeológico}

La Gomera puede considerarse a grandes rasgos como un gran edificio volcánico de evolución compleja, y en la actualidad existen tres modelos evolutivos de la isla (Paris et al., 2005; Cueto et al., 2004; y Ancochea et al., 2006 y Herrera, 2008) que aunque proponen una volcanoestratigrafía a grandes rasgos similar, difieren en la interpretación genética de la misma. El trabajo de Paris et al. (2005) no diferencia ninguna unidad volcanoestratigráfica en la zona de Enchereda, mientras que los trabajos de Cueto et al. (2004) y Ancochea et al. (2006) distinguen en esta zona tres unidades volcanoestratigráfi- cas, que como se detalla más adelante tienen una gran importancia hidrogeológica. De estos dos trabajos, en este artículo se utiliza la terminología de Ancochea et al. (2006) y Herrera (2008), que engloba la mayor parte de los trabajos realizados en La Gomera con anterioridad (p.ej., Bravo, 1964; Cendrero, 1971). En este modelo se diferencian tres fases de crecimiento principales, de más antigua a más moderna (fig. 1 y tabla 1): el Complejo Basal (CB) en el que se han datado muestras entre los 20 y los 11,5 Ma, el Edificio Antiguo (EA) con edades entre los 10,5 y 6,2 Ma, y el Edificio Reciente (ER) datado entre los 5,9 y 2 Ma (Cantagrel et al., 1984; Cueto et al., 2004; Paris et al., 2005; Ancochea et al., 2006; Herrera et al, 2008; Herrera, 2008). A su vez, dentro de cada uno es posible distinguir, en base a su edad, y tipo y características de las coladas, diversas etapas de crecimiento: el Edificio Antiguo se divide en Edificio Antiguo Inferior (EAI) que incluye los Basaltos Antiguos Inferiores y ocasionalmente niveles de brechas volcánicas (tabla 1) y en Edificio Antiguo Superior (EAS), for- 
mado por los Basaltos Antiguos Superiores y dos episodios de rocas sálicas (tabla 1). En el Edificio Reciente también se distinguen dos fases de crecimiento, Edificio Reciente I y II, coexistiendo en la fase más joven materiales de composición desde basáltica hasta sálica (tabla 1).

Cada uno de estos sucesivos edificios tiene además asociado su propio sistema radial de diques máficos. A partir del análisis estadístico de la distribución de los diques verticales de composición máfica de La Gomera, Ancochea et al. (2008) identificaron cuatro enjambres de diques radiales. El más antiguo (S1) con edades comprendidas entre los 9,1 Ma y los 8,4 Ma, se corresponde con los Basaltos Antiguos Inferiores. E1 segundo, S2 (con diques datados entre 8,2 y 6,7 Ma) representa los conductos de ascenso de los Basaltos Antiguos Superiores. Los dos enjambres más recientes (S3 y S4) están formados por diques de composición de máfica a intermedia, al igual que las coladas del Edificio Reciente. Están definidos por diques datados entre 5,5 y 4,4 y entre 5,3 y 4,0 Ma, respectivamente.

En conjunto, el centro de los enjambres de diques maficos (considerado como el centro de la actividad magmática en cada momento) ha emigrado de norte a sur. Teniendo en cuenta que el centro del S4 se encuentra a $8 \mathrm{~km}$ de distancia del $\mathrm{S} 1$, se obtiene que la posición de los centros, y por tanto la actividad basáltica subaérea de la isla, emigró entre los $9 \mathrm{Ma}$ y los 4 Ma unos $8 \mathrm{~km}$ hacia el sur en dirección $\mathrm{N} 170^{\circ}$, a una velocidad media de $1,6 \mathrm{~mm} / \mathrm{año}$ (Ancochea et al., 2008).

Los primeros estudios hidrológicos de la isla definen modelos conceptuales sencillos en los que las coladas del Edificio Reciente son el principal acuífero de la isla (SPA-15, 1975; Porras et al., 1985). El Avance del Plan Hidrológico Insular de la Gomera (APHIG; Soler 1996) elaboró un modelo conceptual para la isla más detallado en el que se diferencia por primera vez al Edificio Antiguo en cuanto a su comportamiento hidráulico. Se generaliza que el EAI puede considerarse, junto con el Complejo Basal, como el zócalo impermeable de la isla que limita en profundidad la circulación del agua subterránea, mientras que el EAS pasa a ser considerado el acuífero más importante de la isla, relegando al acuífero formado por los materiales del Edificio Reciente a un segundo plano como un «multiacuífero colgado central» (Braojos et al., 1996). Además, divide la isla en ocho zonas hidrogeológicas y por primera vez, se describe la superficie piezométrica de la isla como escalonada por el efecto de la red de diques que atraviesan los materiales acuíferos.

En este trabajo definimos, usando criterios geológicos, la zona que hemos denominado Enchereda. Ésta se encuentra limitada por los afloramientos de un zócalo de baja permeabilidad formado por los materiales del EAI en el NO, el Barranco de la Villa por el $\mathrm{O}$ y el $\mathrm{S}$, y la línea de costa al $\mathrm{N}$ y al $\mathrm{E}$ (fig. 1). En la zona el Edificio Reciente aparece representado por afloramientos aislados y de poca extensión (fig. 1). La unidad principal es el EAS, una sucesión de coladas que buzan habitualmente entre $10^{\circ}$ y $20^{\circ}$ hacia el E-ESE hasta disponerse prácticamente horizontales en el acantilado costero, con un espesor total aproximado de 600 metros y atravesadas por diques mayoritariamente de composición basáltica. Los BAS se apoyan discordantes sobre los BAI, situándose entre ellos una brecha volcanoclástica denominada por Bravo (1964) como Aglomerado Volcánico y por Cendrero (1971) como Aglomerado Poligénico. En este trabajo la denominaremos Brechas Volcánicas. Desde el fondo del Barranco de Aguajilva, continuando por la ladera oriental del mismo hasta la carretera de Hermigua a San Sebastián, afloran los Basaltos Antiguos Inferiores, con diversos niveles de brechas a techo.

El máximo de precipitaciones en La Gomera ocurre en la parte central y más elevada de la isla, y en la zona de Enchereda se localiza en los Riscos de Juel (fig. 1), con cantidades estimadas entre 500 y $600 \mathrm{~mm}$ medios anuales, que en la zona de costa son de 100-200 mm/año (Soler et al, 2002; Izquierdo et al., 2010). Así, los valores de recarga calculados para la zona de Enchereda varían desde un máximo en los Riscos de Juel de 90-135 mm medios anuales según Izquierdo et al. (2010) o 200 mm según el APHIG y el Plan Hidrológico Insular (PHIG) (Soler, 1996; Soler et al., 2002), hasta los 20-100 mm medios anuales en la zona de costa (Soler et al, 2002; Izquierdo et al., 2010).

\section{Unidades hidroestratigráficas}

Cada una de las unidades volcanoestratigráficas de la zona de Enchereda (fig. 1) está formada por materiales con propiedades hidrogeológicas diversas, de forma que, a grandes rasgos se pueden identificar tres unidades hidroestratigráficas en esta zona (tabla 1): los Basaltos Antiguos Inferiores, moderadamente permeables; las Brechas Volcáni- 
cas, con baja permeabilidad; y los Basaltos Antiguos Superiores, permeables.

\section{Basaltos Antiguos Inferiores}

Los Basaltos Antiguos Inferiores (BAI) son las coladas basálticas del EAI, principalmente escoriáceas y pahoehoe, atravesadas por una densa red de diques que pertenecen a éste y a los edificios posteriores (Ancochea et al., 2008). Con edades entre los 10,5 y los 8,7 Ma (Ancochea et al., 2006) su permeabilidad original se ha reducido por lo que en la actualidad son materiales de permeabilidad variable. En la zona de Enchereda sus características hidráulicas no se conocen en detalle aunque la existencia de un nivel de brechas en su techo limita el acuífero a los materiales de los Basaltos Antiguos Superiores. En el campo se observa que el grado de alteración de las coladas de los BAI en esta zona no es elevado. Así, las coladas con textura vacuolar presentan la mayor parte de las vacuolas sin rellenar, mientras que en los BAI de otros sectores de la isla éstas se encuentran rellenas habitualmente de carbonatos y zeolitas (Herrera, 2008). Por ello, esta unidad en Enchereda presenta características que hacen suponer que sea moderadamente permeable.

\section{Brechas Volcánicas}

A techo de los BAI, en las paredes del Barranco de Aguajilva y en la pared oriental del Barranco de Hermigua, afloran las Brechas Volcánicas, interpretadas en los trabajos más recientes (Cueto et al., 2004; Ancochea et al., 2006) como brechas de tipo debris-avalanche generadas durante la destrucción del Edificio Antiguo Inferior. Se trata de brechas sin estructuración interna, de composición variable, generalmente polimícticas. Los fragmentos son de diversos tipos de basaltos (plagioclásicos, olivínico piroxénicos, afaníticos y ankaramitas) entre angulosos y subangulosos, con tamaños desde $2 \mathrm{~cm}$ hasta más de $20-30 \mathrm{~cm}$ y que flotan en una matriz arenoarcillosa con cristales aislados de piroxeno (Cueto et al., 2004; Ancochea et al., 2006; Herrera, 2008), lo que las confiere un comportamiento hidrogeológico muy poco permeable. Por tanto, reducen el paso del agua en la vertical desde los Basaltos Antiguos Superiores hacia los Basaltos Antiguos Inferiores.

\section{Basaltos Antiguos Superiores}

Es la unidad hidrogeológica más importante de Enchereda y en general de la isla, ya que forma el acuífero basal de la misma, siguiendo la terminología empleada para los acuíferos hawaianos. Los Basaltos Antiguos Superiores (BAS) conforman el EAS, junto con dos episodios de rocas sálicas, y están formados principalmente por alternancias de coladas escoriáceas y masivas. Las coladas tienen una estructura vertical muy definida, con una zona escoriácea con una permeabilidad relativamente alta a muro; por encima, una zona central masiva de porosidad baja; y por último, una zona escoriácea formada por degasificación altamente porosa aunque no siempre con permeabilidad elevada (Custodio, 1978). En el caso de las coladas escoriáceas del BAS la parte central masiva puede tener un espesor muy reducido o ni siquiera aparecer. La permeabilidad actual de estas coladas es similar a la original aun cuando su edad está comprendida entre los 8,6 y los 6,2 Ma (Ancochea et al., 2006) y la malla de diques que la atraviesa tiene, en general, una densidad menor que en el caso de los BAI. Intercalados con las coladas existen niveles piroclásticos que actúan como niveles impermeables locales que dan lugar a pequeños manantiales estacionales con un bajo caudal.

\section{Geometría del acuífero}

En este trabajo se han cartografiado, tanto en el campo como mediante ortofoto aérea (1:5.000), los afloramientos de las Brechas Volcánicas que aparecen en la base de los materiales del EAS (fig. 2A) y se ha tenido en cuenta la información litológica de los sondeos existentes en la zona para hacer una reconstrucción geométrica de esta unidad hidroestratigráfica mediante diversos cortes geológicos (fig. 2B). En el Anexo al PHIG de Ensayos de Bombeo (Soler et al., 2002) se describen las columnas geológicas de los sondeos de Juel, El Helechal y Enchereda I, que alcanzan el nivel de Brechas Volcánicas que limita el acuífero (fig. 2A) y de Los Campos que no llega a las brechas, quedando en materiales del EAS. Del resto de sondeos no se tiene información. Por último, la galería de Ipalán en sus $2.089 \mathrm{~m}$ de longitud atraviesa únicamente materiales del EAS.

Las Brechas Volcánicas afloran a techo de los BAI en las paredes del Barranco de Aguajilva y en 


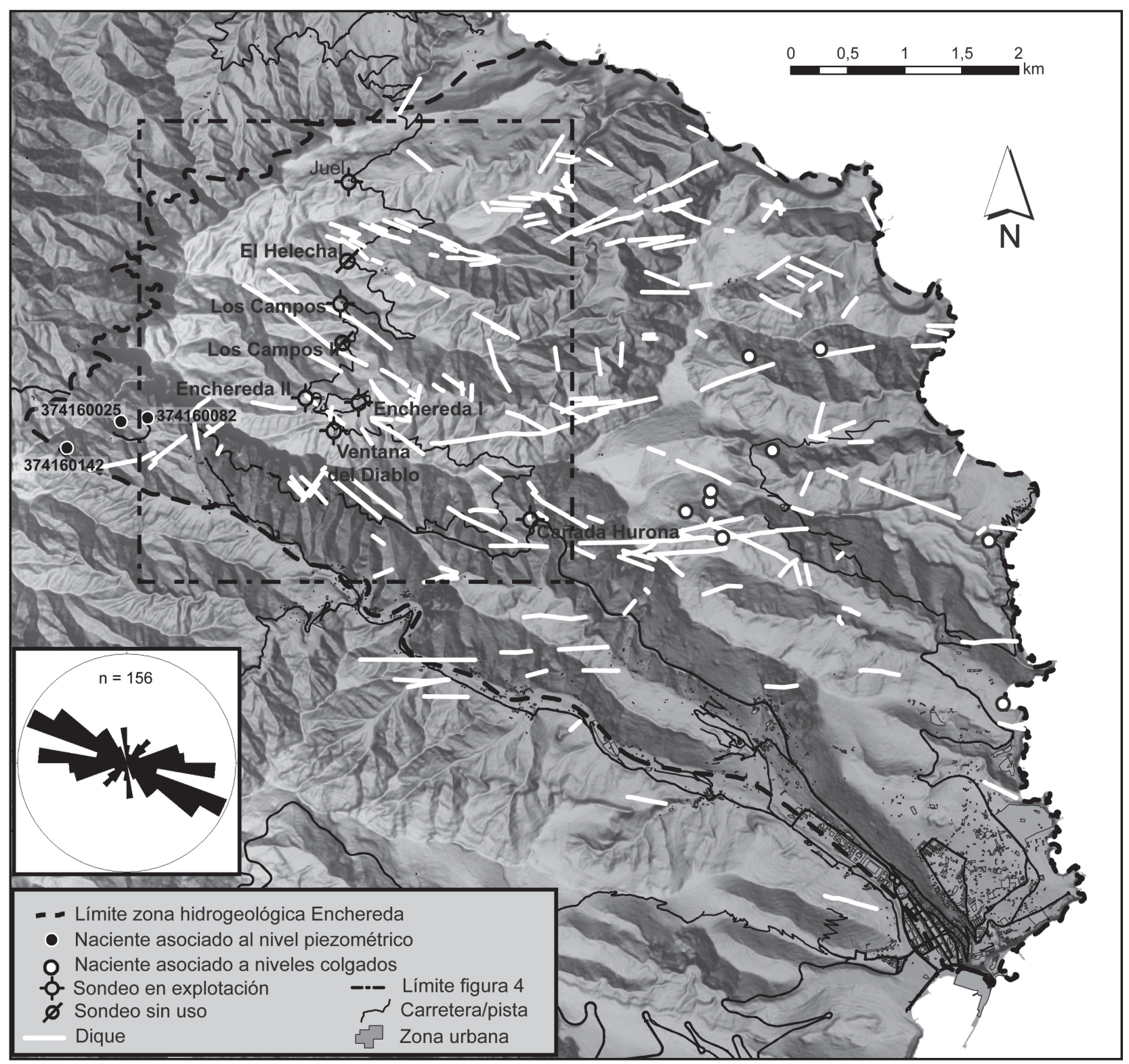

Fig. 3.-Diques cartografiados mediante fotografía aérea y ortofoto y localización de los manantiales y sondeos.

la pared oriental del Barranco de Hermigua, en los límites $\mathrm{SO}$ y $\mathrm{N}$ de la zona respectivamente. En el primer caso son cortadas por la carretera TF-711 en dos ocasiones (fig. 2A) mientras que en el Barranco de Hermigua no es posible acceder a los afloramientos. En la figura 2A se muestra el mapa geológico de la zona con los afloramientos de brecha que junto con las cotas conocidas de la brecha en los sondeos han permitido realizar, por un lado isolineas de cota del techo de la misma y, por otro, cortes geológicos representativos (fig. 2B). Tanto los con- tornos como los cortes (figs. 2A y 2B) muestran una geometría coherente con un buzamiento general hacia el ESE de aproximadamente $13^{\circ}$ que concuerda con el hecho de que este depósito no aflore en los acantilados de la costa donde sólo lo hacen los materiales del EAS.

El flujo del agua en la zona de Enchereda previsiblemente seguirá una dirección de flujo desde la zona de máxima recarga en los Riscos de Juel hacia el SE, donde descargará a lo largo de la costa (fig. 1), lo que se verá además favorecido por el hecho de 
que el buzamiento de las coladas de los BAS y de las Brechas Volcánicas que limita el acuífero llevan esa misma dirección.

\section{Características de la red de diques}

Este movimiento regional hacia el SE del agua en el acuífero, puede verse influenciado por la presencia de diques en la zona. Por ello, en este trabajo se han cartografiado los diques de la zona mediante mediciones en el campo a lo largo de la pista de Enchereda (figuras 1 y 3) que recorre la parte alta (occidental) de la zona de Sur a Norte y en el interior de la galería de Ipalán, complementadas con el estudio de fotografía y ortofoto aérea (escalas 1:18.000 y 1:5.000 respectivamente) (fig. 4).

Los diques más fácilmente identificables mediante fotografía y ortofoto aérea son aquéllos que están exhumados o semi-exhumados (conocidos localmente como «taparuchas») que presentan principalmente una dirección E-O y llegan a aflorar durante kilómetros (fig. 3). Además, en las paredes de los barrancos se identifican diques pertenecientes a otras familias, predominantemente con dirección NO-SE y en menor medida con direcciones N-S y NE-SO (fig. 3). A lo largo de la pista de Enchereda y en el interior de la galería de Ipalán se han medido 153 y 40 diques respectivamente (fig. 4A) identificándose tres familias de diques con direcciones NO-SE, N-S y E-O (fig. 4B) las cuales son consistentes con las obtenidas en nuestra cartografía de gabinete y por Ancochea et al. (2008) en su estudio de los diques básicos de la isla para esta zona. A pesar de que en el estudio de las fotografías aéreas la dirección E-O es similar en ocurrencia a la NOSE (fig. 3) la cartografía de campo muestra que la familia con un mayor número de diques es la NOSE (con una dirección principal N120; fig. 4B) y que la dirección NE-SO es mínimamente representativa.

Los diques de la familia NO-SE cartografiados en la zona de Enchereda están probablemente relacionados con la construcción del Edificio Antiguo Superior, puesto que convergen en el centro asignado a esta fase de crecimiento (Ancochea et al., 2008). Los diques de dirección E-O más septentrionales de la zona podrían corresponder al mismo centro. El resto de los diques de esta dirección (EO) forman probablemente parte de los enjambres del Edificio Reciente ya que son radiales a sus centros de emisión, al igual que los diques NE-SO. Los diques de la familia de dirección N-S no apuntan a ninguno de los cuatro centros de diques radiales definidos por Ancochea et al. (2008) ni existen otros criterios geocronológicos que permitan determinar su edad.

A lo largo de la pista, se ha realizado un cálculo de la densidad de diques proyectados a la dirección N30, perpendicular a la predominante (N120). En una zona de aproximadamente $1,5 \mathrm{~km}$ de ancho entre los sondeos de El Helechal y Enchereda II (fig. 4) la densidad de diques es de entre 10 y 15 diques/100 metros, disminuyendo hacia los extremos norte y sur a 4 diques $/ 100 \mathrm{~m}$. En el caso de la galería que se encuentra situada $400 \mathrm{~m}$ por debajo de la pista, la densidad media de diques es de 3-4 diques/100 m proyectados a la dirección N30, similar a la del extremo sur de la pista.

\section{Niveles piezométricos: espesor de la zona saturada}

Los datos disponibles del nivel piezométrico provienen por un lado de la existencia de manantiales y por otro de las captaciones que se encuentran en el interior de la zona, los sondeos y la galería de Ipalán. Los 12 manantiales que aparecen (fig. 3) pueden dividirse en dos grupos según su situación estratigráfica (Navarro et al., 1991). El primero, situado en la parte más occidental de la zona (fig. 3) estaría asociado a la diferencia de permeabilidades entre los BAS y las Brechas Volcánicas ya que surgen en el contacto entre ambas unidades. Aunque no descargan un caudal importante $(<1 \mathrm{l} / \mathrm{s}$; Navarro et al., 1991), sí aportan información sobre la situación del nivel piezométrico en ese área puesto que surgen en el contacto con el límite impermeable del acuífero (cotas 720-730 msnm). El resto de manantiales situados en la parte central de la zona y en lo alto de los acantilados costeros (fig. 3) no representan, por el contrario, puntos de descarga del acuífero, por encontrarse a una cota superior a la del nivel piezométrico regional en las zonas en las que aparecen y estar asociados a niveles piroclásticos o almagres locales.

El nivel piezométrico se conoce, además, en los seis sondeos que se encuentran en explotación dentro de la zona así como en la galería de Ipalán, en cuyo interior, se han realizado tres sondeos horizontales de los cuales dos han alumbrado agua (tabla 2). Además, existe un sondeo en la bocamina de la galería del cual también se conoce la posición del 


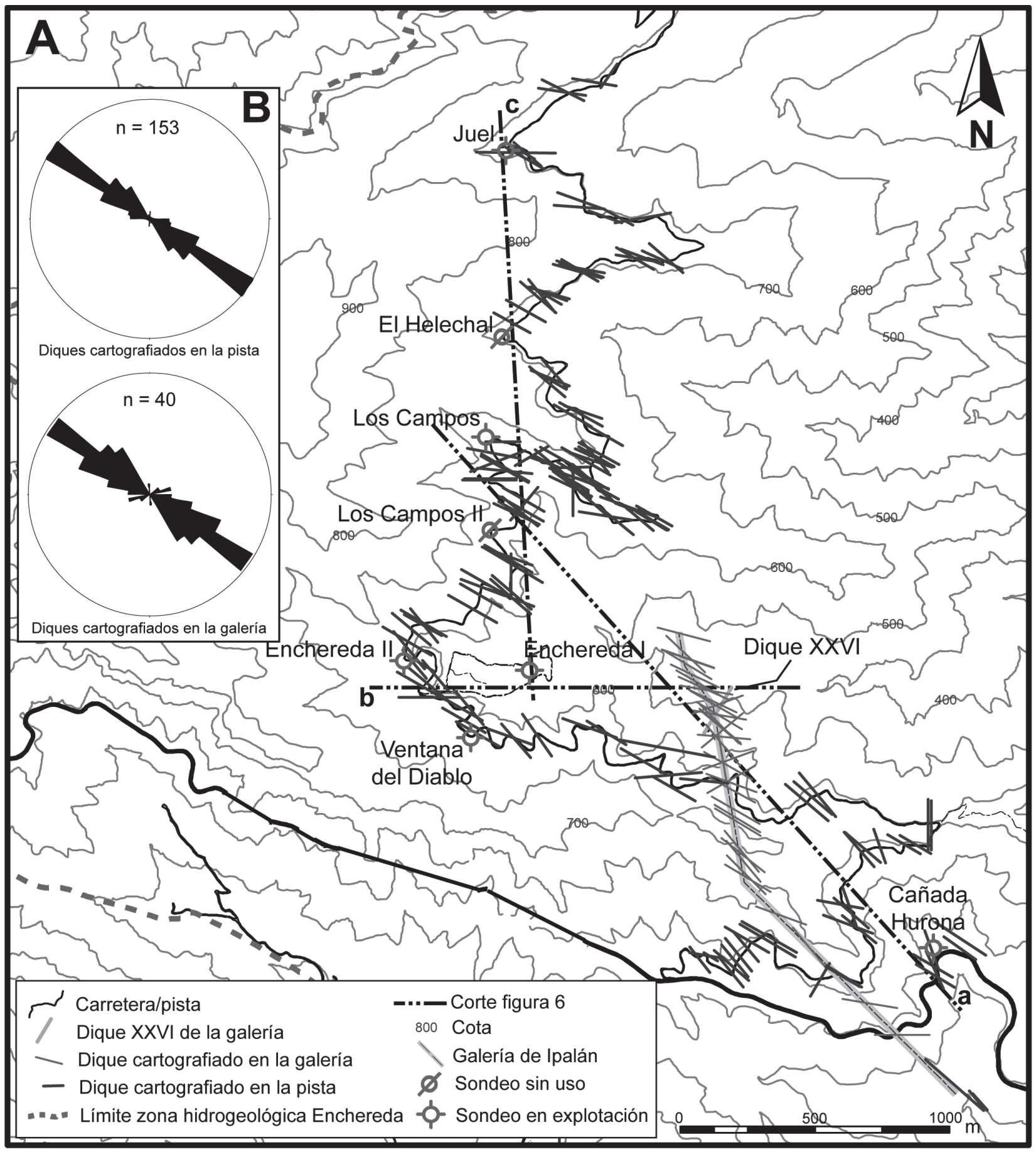

Fig. 4.-A) Mapa de los diques cartografiados en el campo en la zona de Enchereda y en la galería de Ipalán. En línea discontinúa se representan los cortes de la figura 6; B) Rosas de direcciones de los dos grupos de diques medidos. 
Tabla 2.--Resumen de los niveles piezométricos conocidos en la zona de Enchereda

\begin{tabular}{lcrr}
\hline & Abril $2007(\mathrm{msnm})$ & Abril 2008 (msnm) & Abril 2009 (msnm) \\
\hline Sondeo Cañada Hurona & 39,7 & 33,7 & 33,6 \\
Sondeo Ventana del Diablo & 371,5 & 361,63 & 347,1 \\
Sondeo Enchereda II & 383 & 380 & 367 \\
Sondeo Enchereda I & 266 & 257,8 & 240,9 \\
Sondeo Los Campos & 461 & 454 & 450,7 \\
Sondeo Juel & 478,4 & 466 & 462,7 \\
Galería & $263^{\text {a }}$ & - & $237^{\mathrm{b}}$ \\
Sondeo Sh-1 & - & - & 235 \\
Sondeo Sh-2* & - & - & 245 \\
Sondeo bocamina galería & - & -20 & -2 \\
\hline
\end{tabular}

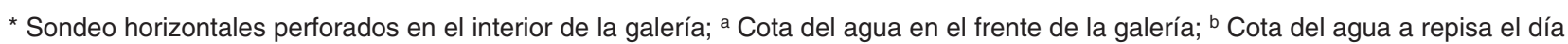
1 de Abril de 2009.

nivel. En la tabla 2 se puede observar el claro descenso de los niveles piezométricos en el acuífero debido, por una parte, a las extracciones para abastecimiento de los sondeos y por otra, a la perforación de la galería, llegando a haber descendido hasta $26 \mathrm{~m}$ en el sondeo Enchereda I desde diciembre de 2007 hasta abril de 2009.

Las estimaciones de recarga existentes en la parte alta de la zona de estudio varían entre 90 y $200 \mathrm{~mm}$ medios anuales (Soler et al., 2002; Izquierdo et al., 2010), por lo que el volumen máximo de agua que entra anualmente en la parte alta del acuífero es de entre 0,3 y $0,8 \mathrm{Hm}^{3}$. Esta cantidad es claramente inferior a $1 \mathrm{Hm}^{3}$ anual que se extrae del conjunto de los sondeos, lo que explica los descensos del nivel piezométrico que se observan en los últimos años en todas las captaciones (tabla 2).

En la figura 5 se representa tridimensionalmente la parte final de la traza de la galería de Ipalán junto con los diques cortados por ella y los sondeos horizontales perforados en su interior. El nivel freático previo a la galería se conoce ya que un sondeo horizontal precedía a la perforación. Así, sabemos que tras el dique XXVI (N30; $2 \mathrm{~m}$ de espesor) se encontraba a una cota de $263 \mathrm{msnm}$, aproximadamente 30 $\mathrm{m}$ por encima del suelo de la galería en ese punto. Esto sugiere que este dique actuaba como barrera impermeable sobreelevando el nivel piezométrico en ese punto ya que como se observa en la figura 5 la dirección del mismo es perpendicular a la dirección de flujo. Una vez vaciado el «compartimento» creado por ese dique y con el caudal estabilizado en aproximadamente $9 \mathrm{l} / \mathrm{s}$ en el metro 1.873, el agua sale de repisa por la galería por lo que se considera que el nivel freático se encuentra a esa cota, es decir, a 237 msnm (fig. 5; tabla 2). Además, en el sondeo Sh-1, emboquillado a ras del suelo, el nivel piezométrico se encuentra a los $235 \mathrm{msnm}$ (fig. 5), lo que concuerda con el nivel freático para la galería. Estos valores implican un descenso del nivel freático para la galería de $26 \mathrm{~m}$. De los otros dos sondeos horizontales que existen en la galería, el sondeo del frente no encontró agua, mientras que en el sondeo Sh-2 el nivel se encuentra a $245 \mathrm{msnm}$ (fig. 5).

Los datos conocidos de los niveles piezométricos no son suficientes como para calcular las isopiezas en la zona de estudio. Sin embargo, utilizando los datos de Abril de 2009 (tabla 2) se han realizado tres cortes con direcciones N120, N90 y N180 (fig. 6) en los que se representan dichos valores así como los diques cartografiados con direcciones diferentes a la de flujo (N120). Como se aprecia en la figura 6 , el relieve de la isla hace que el nivel piezométrico vaya descendiendo de la zona de máxima recarga en la cumbre hacia el mar al SE, influida por el buzamiento de las coladas del BAS y de la brecha que limita el acuífero. En el corte paralelo a la dirección del flujo regional del agua (fig. 6, corte a) la superficie piezométrica bien podría ser representada como una superficie continua de pendiente suave, de aproximadamente $5 \%$, en la que los diques no actuarían como pantalla impermeable. Sin embargo, en los cortes b y c de la figura 6 , con dirección O-E y N-S respectivamente, se observa cómo entre los sondeos de Enchereda II y Enchereda I y Los Campos y Enchereda I, en el caso de que la superficie piezométrica fuera continua, ésta tendría una pendiente de entre el $20 \%$ y el $23 \%$. Podría deducirse por tanto, tras ver la diferencia de potencial que existía tras el dique XXVI en el interior de la galería y los cortes realizados que, en realidad, la superficie piezométrica se encuentra escalonada por efecto de los diques. Además, como se observa en 


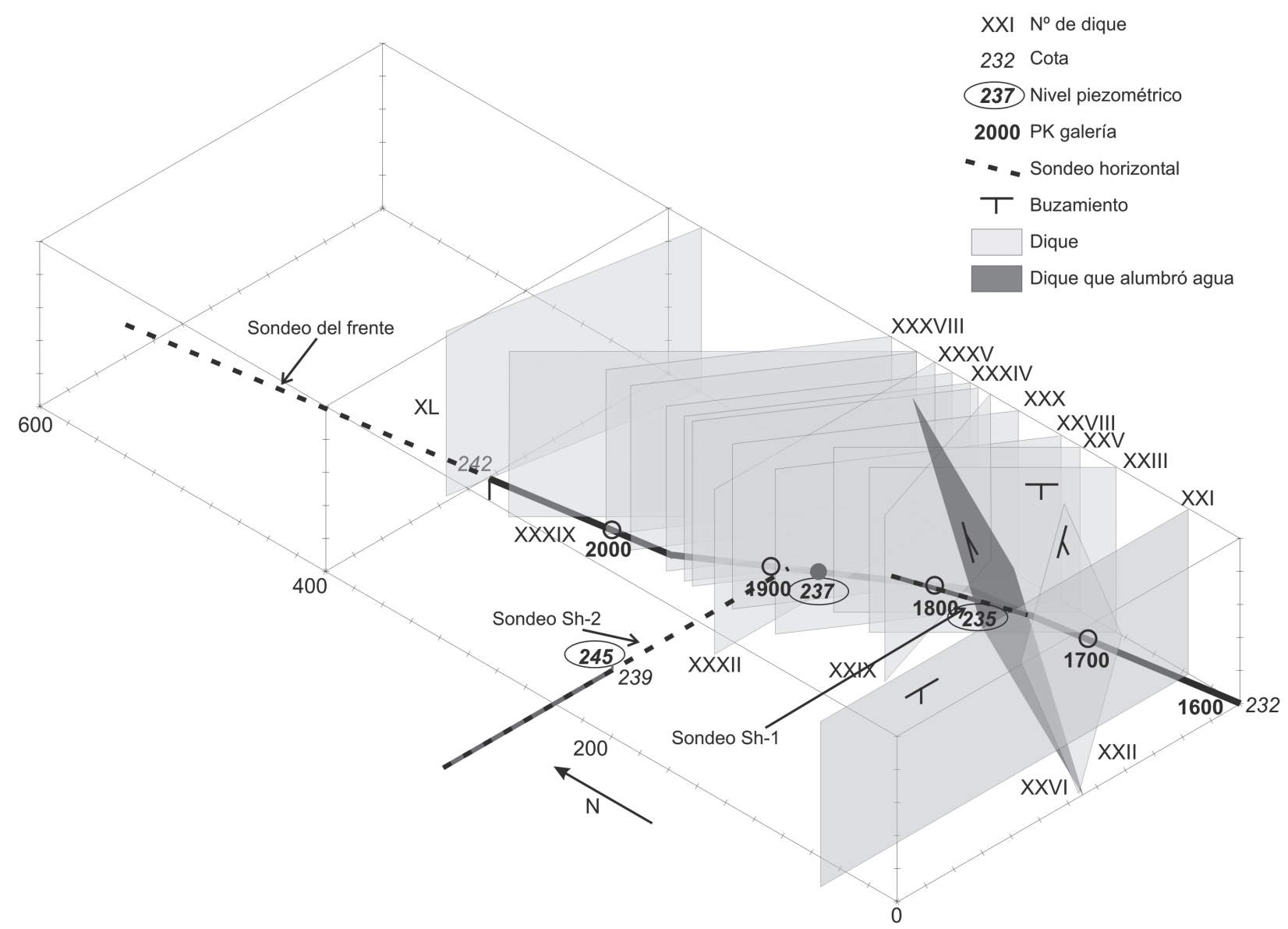

Fig. 5.-Representación tridimensional de la traza de la galería desde el metro 1.600 hasta el frente con las cotas a las que se encuentra el nivel piezométrico, los diques numerados en números romanos y los sondeos horizontales existentes en el interior de la galería. En gris oscuro se representa el dique XXVI $\left(\mathrm{N} 30^{\circ}\right)$ tras el cual la galería alumbró agua.

el corte c son principalmente los diques N-S (direcciones entre $\mathrm{N}^{\circ}$ y $\mathrm{N}^{\circ} 5^{\circ}$ ) y los NE-SO (direcciones entre $\mathrm{N} 30^{\circ}$ y $\mathrm{N} 40^{\circ}$ ) los que sobreelevan el nivel piezométrico mientras que los E-O parecen influir en menor medida el movimiento del agua en el acuífero. Por tanto, a pesar de que la familia de diques NE-SO no presenta un elevado número de diques, su influencia en el acuífero es clave al ser perpendiculares a la dirección de flujo regional.

El hecho de que el límite del acuífero sea un brecha volcanoclástica y que la superficie piezométrica sea escalonada, hace que el espesor saturado del acuífero varíe según el «compartimento» en el que nos encontremos. De esta forma, en los dos lugares en los que se conoce tanto la posición del nivel como la de la brecha, el espesor saturado en uno, es varias veces superior al del otro (tabla 3; fig. 6).

\section{Discusión}

A pesar de que el APHIG (Soler, 1996) realiza una división de La Gomera en ocho sectores hidrogeológicos, ésta se basa en límites administrativos de forma que, hay una zona 0 , que abarca la zona central de la isla en la que se encuentra el Parque Nacional de Garajonay, y las otras 7 se corresponden con los municipios de la isla. Por tanto, hasta el momento no se habían utilizado criterios hidrogeológicos para realizar una correcta zonificación de la isla. En este trabajo proponemos aplicar la clasificación definida para los acuíferos de Hawai. En ella existen tres niveles jerárquicos de división que de mayor a menor son: aquifer sector, aquifer system y aquifer types (Mink \& Sumida, 1984). Los primeros consideran límites administrativos e históricos, de forma que los aquifer system incluidos en ellos se 
(a)

NO

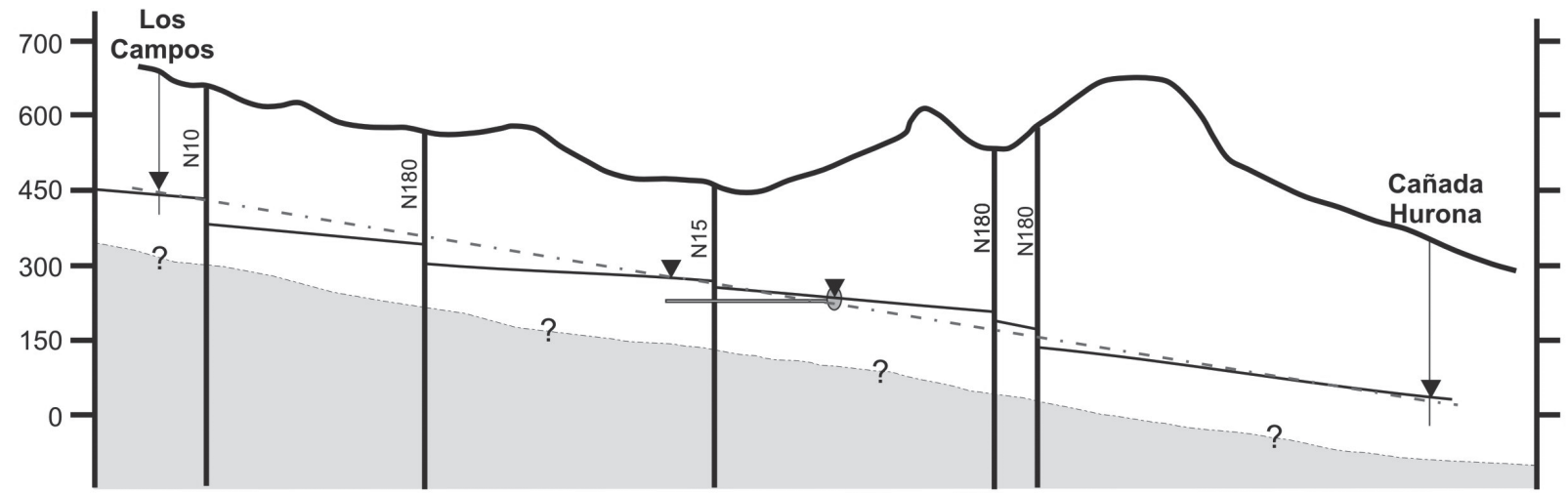

(b)

o

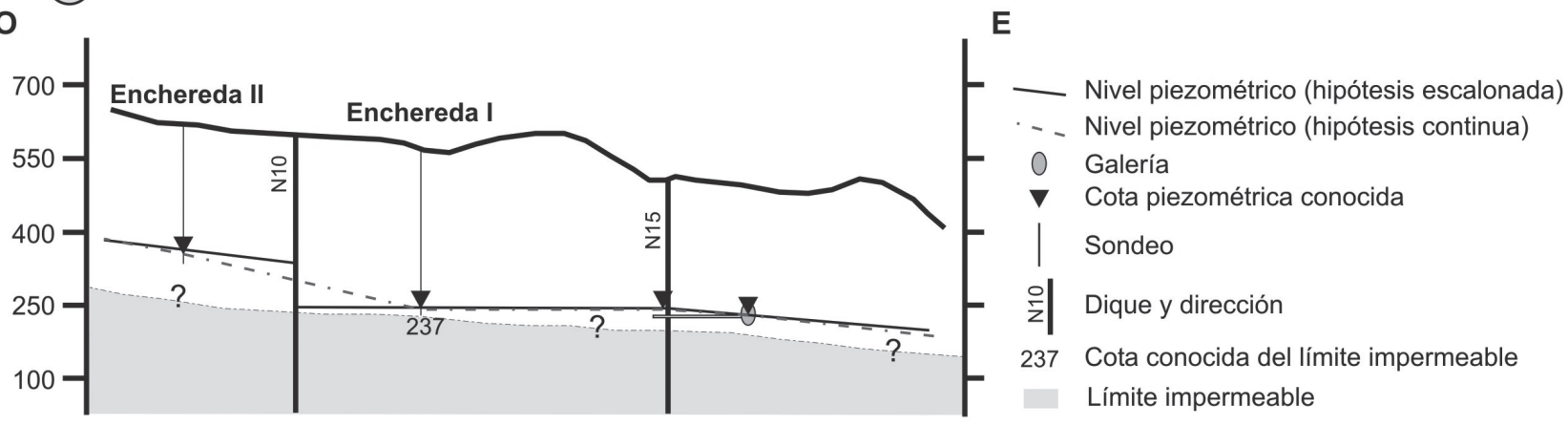

(C)

$\mathbf{N}$

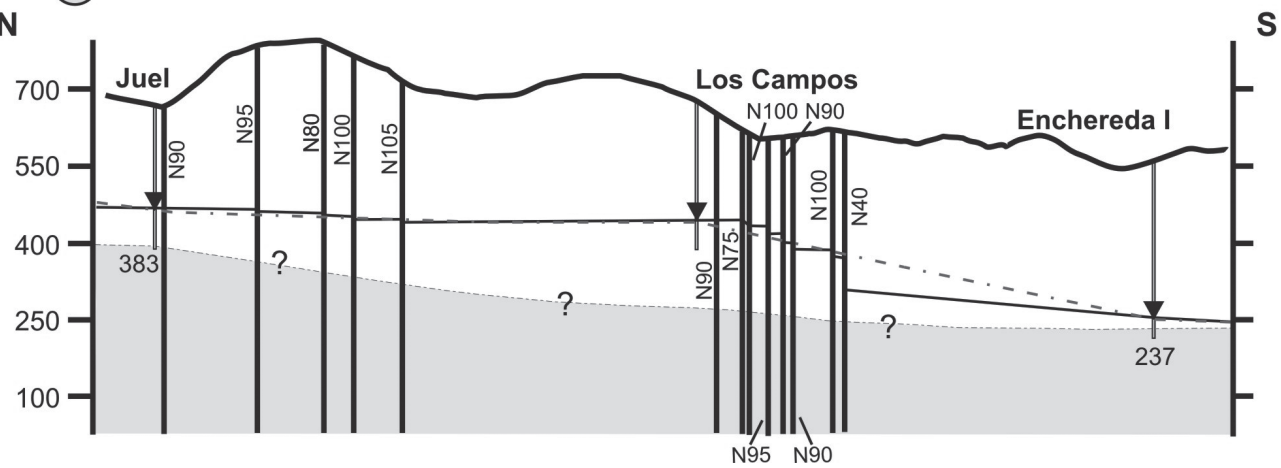

Fig. 6.-Cortes esquemáticos de la superficie piezométrica representada como una superficie continua (línea discontinua) y como una superficie escalonada (línea continua). Se representan los diques cartografiados en campo y en fotografía aérea que no pertenecen a la familia principal con dirección NO-SE.

encuentran conectados hidráulicamente en cierto grado. Los aquifer system representan la unidad principal de gestión ya que se definen como zonas en las que la superficie piezométrica está hidráulicamente conectada, a pesar de que las condiciones hidrogeológicas puedan cambiar. Estos cambios en las condiciones hidrogeológicas son los que definirían los aquifer types. La zona de Enchereda, definida en este trabajo, se corresponde con un aquifer system en el que la superficie piezométrica está hidráulicamente conectada a pesar de que las condiciones hidrogeológicas cambian a lo largo de la 
Tabla 3.-Niveles piezométricos y espesor de la zona saturada en los años 2007 y 2009 en los sondeos en los que se conoce el nivel y la profundidad de la brecha

\begin{tabular}{|c|c|c|c|c|c|c|}
\hline \multirow[b]{2}{*}{ Sondeo } & \multicolumn{2}{|c|}{ Nivel piezométrico (msnm) } & \multirow[b]{2}{*}{ Cota de la brecha (msnm) } & \multicolumn{2}{|c|}{ Espesor acuífero (m) } & \multirow{2}{*}{$\begin{array}{l}\text { Descenso nivel } \\
\text { piezométrico }(\mathrm{m})\end{array}$} \\
\hline & abril 2007 & abril 2009 & & abril 2007 & abril 2009 & \\
\hline Enchereda I & 265,9 & 240,9 & 237 & 28,9 & 3,9 & 25 \\
\hline Juel & 478,4 & 462,7 & 383 & 95,4 & 79,7 & 15,7 \\
\hline
\end{tabular}

zona. De esta forma, la definición de estos límites supone poder gestionar de forma sostenible e independiente los recursos hídricos de este acuífero en relación con el resto de la isla.

En algunos modelos hidrogeológicos de Canarias, la existencia de niveles piezométricos a cotas altas en el interior de algunas islas es explicado por la existencia de un núcleo de baja permeabilidad en el centro insular (Custodio, 1978; 2004; 2007). Sin embargo, en el caso del sistema acuífero de Enchereda este modelo no puede ser aplicado, ya que el núcleo impermeable de la isla, formado por el Complejo Basal y las zonas más alteradas e intruidas por diques de los Basaltos Antiguos Inferiores, queda situado varios kilómetros hacia el Noroeste. La observación de campo de los Basaltos Antiguos Inferiores en la zona de estudio permite describirlos como materiales que no han experimentado un grado de alteración elevado de forma que apenas existe mineralización secundaria y las partes escoriáceas de las coladas no han sido transformadas en arcillas, alteraciones que sí se observan en estos materiales en otras zonas de la isla. Así, a pesar de que el APHIG limita la permeabilidad general en la isla de esta unidad a niveles residuales (Braojos et al., 1996), en este trabajo proponemos que en el sistema acuífero de Enchereda su permeabilidad podría ser suficiente para su explotación. Sin embargo, su papel como potencial acuífero queda reducido por la existencia a techo de las Brechas Volcánicas con características hidrogeológicas muy poco permeables que deben limitar severamente el flujo del agua en la vertical desde los BAS, y a su escasa zona de recarga directa en su único afloramiento del barranco de Aguajilva (fig. 2).

Esta primera reconstrucción de la geometría de las brechas volcanoclásticas que afloran en el sector NE de La Gomera presenta una coherencia y morfología similar a la de otras brechas interpretadas como depósitos de debris-avalanche generadas en grandes deslizamientos de flanco de los edificios volcánicos. Estas brechas son localmente conocidas como «mortalón» en hidrogeología en Canarias y para el caso del acuífero de Icod - Cañadas, (Tenerife) Márquez et al. (2008) realizaron una reconstrucción detallada de la geometría de la misma, obteniendo un buzamiento de $5^{\circ}$ hacia el NNO. La geometría de los "mortalones" de La Orotava y Güimar, también en la isla de Tenerife, no ha sido reconstruida en detalle aunque a partir de los cortes geológicos realizados por Navarro y Farrujia (1989) se pueden calcular un buzamiento de aproximadamente $6^{\circ}$ hacia el $\mathrm{N}$ y $9^{\circ}$ hacia el SE respectivamente. Esto supone un buzamiento menor que el calculado para la brecha de Enchereda implicando que, bien los procesos que la formaron, bien las condiciones en las que se generó fueron diferentes. Por otro lado, trabajos realizados en otras islas volcánicas como Galápagos (d'Ozuville et al., 2008) obtienen mediante técnicas geofísicas una geometría con características similar a la del acuífero Icod - Cañadas. Sin embargo, los autores interpretan que el límite inferior del acuífero se debe a un paleosuelo, aunque la extensión y geometría de esa unidad sugieren que sea una brecha de debris-avalanche de un deslizamiento todavía no caracterizado e identificado la que esté actuando como límite inferior de ese acuífero, en lugar de un paleosuelo. En la depresión del Grand Brûlé en la isla de Reunión, Descloitres et al. (1997) obtienen mediante métodos geofísicos un acuífero con geometría similar a la de Galápagos cuyo límite inferior interpretan como el depósito resultante de un deslizamiento de flanco del volcán. La mayoría de los autores coinciden con esta interpretación aunque trabajos más recientes (Michon \& Saint-Ange, 2008) argumentan que dicha morfología es debida a un spreading generalizado del volcán por efecto del núcleo hidrotermal. En todo caso, a efectos hidrogeológicos, la caracterización de estas unidades supone conocer el límite inferior de los acuíferos volcánicos que se encuentran sobre ellas y por tanto, poder conocer su espesor saturado y su capacidad de almacenamiento. Esta información es imprescindible para una buena 
gestión, especialmente en islas volcánicas en las que los recursos hídricos suelen ser más escasos que en otras zonas.

El estudio de los diques que afloran en el sistema acuífero de Enchereda ha permitido valorar y evaluar su posible influencia en el flujo regional del agua en el acuífero. Así, el hecho de que la galería de Ipalán alumbrara agua tras atravesar el dique XXVI (con dirección N30, buzamiento 70SE y un espesor de $2 \mathrm{~m}$; fig. 5), el cual provocaba una sobreelevación del nivel piezométrico de al menos $28 \mathrm{~m}$ medido en el sondeo de avance de la galería, parece indicar que los diques de esta familia impiden o ralentizan el flujo general del agua en el acuífero. Además, el sondeo horizontal Sh2 muestra una diferencia de cota de $10 \mathrm{~m}$ entre el nivel piezométrico de la galería y el detectado en el sondeo al alumbrar agua a los $120 \mathrm{~m}$ de longitud (fig. 5). Este salto del nivel piezométrico podría estar relacionado con el dique de dirección N15 que se observa en la foto aérea entre la traza de la galería y el frente del sondeo. Por otro lado, el hecho de no alumbrar agua tras los diques con dirección NO-SE sugiere que esta familia de diques canaliza el agua que debido al buzamiento de las coladas y la geometría de la brecha tiene esa misma dirección de flujo regional.

Por tanto, en la parte alta del sistema acuífero de Enchereda, los diques de la familia NO-SE canalizan el agua desde la zona de recarga en los Riscos de Juel hasta su descarga en el mar. Las otras dos familias sin embargo, presentan comportamientos diferentes. Por un lado, los diques N-S y los NE-SO (dique XXVI de la galería) al ser perpendiculares a la dirección de flujo (fig. 5) actúan como barreras de baja permeabilidad que aumentan la anisotropía y compartimentan los canales creados por los diques de la familia NO-SE. Por otro, los diques con dirección E-O parecen influir en menor medida en el flujo regional del agua en el acuífero (corte c fig. 6). La existencia de diferentes familias de diques se debe a que cada uno los edificios subaéreos de La Gomera tiene asociado un enjambre de diques radial y puesto que la actividad magmática ha ido migrando hacia el sur (Ancochea et al., 2008) los diferentes enjambres se entrecruzan. De esta forma, en el sector estudiado del sistema acuífero de Enchereda, los diques de las familias N-S y NE-SO parecen sobreelevar localmente el nivel piezométrico, formando una superficie escalonada en vez de continua (fig. 6). Este escalonamiento de la superficie piezométrica se produciría al menos en la parte alta del sistema acuífero, a lo largo de una longitud de más de 3 kilómetros en la dirección principal de flujo (fig. 6). Teniendo en cuenta que el sistema acuífero tiene una longitud de menos de $10 \mathrm{~km}$ (fig. 3) el escalonamiento del nivel piezométrico sería una característica de una parte importante del sistema.

En Hawai, este tipo de acuíferos en los que el agua se encuentra en las coladas basálticas quasiatrapada entre diques verticales están ampliamente estudiados y caracterizados (p. ej. Takasaki \& Mink, 1985) ya que al encontrarse en zonas elevadas la extracción del agua es sencilla y de bajo coste sin el riesgo de sufrir intrusión marina (Lau \& Mink, 2006). Debido a que las zonas de rift son las que presentan una mayor densidad de diques, es en ellos donde es más frecuente encontrar este tipo de acuíferos. De hecho, es en estas zonas de rift en las que los acuíferos se definen para Hawai ya que en la zona central de los rift la densidad media de diques es de entre 6 y 12,5 diques cada $100 \mathrm{~m}$, decreciendo lateralmente hasta densidades de 1 dique cada 100 m (Takasaki \& Mink, 1985). En Canarias, encontramos acuíferos de estas características en varias islas, como por ejemplo en Tenerife tanto en la Dorsal NO como en la NE, en las que los diques se comportan como barreras de permeabilidad baja o nula obstaculizando el flujo horizontal del agua en sentido cumbre - mar (Navarro \& Farrujia, 1989) presentando densidades que varían en profundidad desde 20 a 4 diques cada $100 \mathrm{~m}$ (Navarro, 1974).

Aunque el estudio de los diques máficos de La Gomera sólo ha determinado la existencia de varios enjambres de diques radiales superpuestos (Ancochea et al., 2008) en la zona de estudio el sistema acuífero presenta unas características similares a las definidas para las zonas de rift volcánicas con una densidad de entre 4 y 15 diques cada $100 \mathrm{~m}$ a lo largo de la zona alta de la pista de Enchereda, similar a la mencionada en otras zonas de rift en Hawaii y Canarias (ej., Takasaki \& Mink, 1985; Navarro, 1984).

El modelo conceptual propuesto en este trabajo para explicar la existencia de niveles piezométricos elevados en el interior de la isla de La Gomera en el sistema acuífero de Enchereda, se basa en la combinación de: 1) un nivel impermeable generado en uno o varios episodios de destrucción del edificio volcánico, con 2) la existencia de varios enjambres entrecruzados de diques. Este tipo de estructura geológica es suficiente para generar niveles pie- 
zométricos a cotas elevadas y grandes pendientes de la superficie piezométrica considerando el conjunto del sistema acuífero. Sin embargo, en este trabajo se muestra que cuando esa superficie piezométrica se analiza en detalle, se observa que puede ser representada como una superficie escalonada por los diques, aunque se represente como continua a nivel del macizo. Al menos en el caso del sistema acuífero de Enchereda este escalonamiento de la superficie piezométrica no debe considerarse como un detalle local, ya que afecta a una extensión importante del sistema. Por ello, proponemos que en otras islas en las que se ha minimizado el papel de los diques en la definición de la superficie piezométrica y en el comportamiento regional del agua subterránea como en Reunión (Join et al., 2005), en la Isla de Pascua (Herrera \& Custodio, 2008) o en el Edificio Famara (Lanzarote; Custodio \& Saenz Oiza, 1972) el papel de los diques debería ser reevaluado, más aún teniendo en cuenta que dichas islas cuentan con varios centros de emisión por lo que es posible que existan zonas en las que los acuíferos se encuentren compartimentados por diques entrecruzados. En estos casos, proponemos que el estudio detallado de los enjambres de diques es clave para determinar la localización de posibles obras de captación de los recursos hídricos de esos acuíferos.

\section{Conclusiones}

En este trabajo se ha definido por primera vez el sistema acuífero de Enchereda (aquifer system según la nomenclatura de clasificación para el archipiélago de Hawai) en base a los conocimientos hidrogeológicos de La Gomera, por ser ésta una unidad hidrogeológica separada hidráulicamente del resto del sistema acuífero de la isla.

De esta forma, en el sistema acuífero de Enchereda se han definido tres unidades hidroestratigráficas: los Basaltos Antiguos Inferiores, moderadamente permeables; las Brechas Volcánicas, de baja permeabilidad; y los Basaltos Antiguos Superiores, permeables. Estos últimos forman el acuífero principal de la zona de Enchereda.

Al menos en la parte alta de este acuífero, el límite inferior está definido por las Brechas Volcánicas, interpretadas como generadas por procesos de debris-avalanche por autores previos, las cuales presentan una geometría coherente buzando aproximadamente $13^{\circ}$ hacia el ESE, condicionando el flujo regional que circula por tanto desde su zona de recarga máxima en los Riscos de Juel hacia el mar, con una dirección NO-SE.

El sistema acuífero se encuentra compartimentado por diques pertenecientes a cuatro familias que influyen de diferente forma en el flujo regional. Por un lado, los diques de la familia NO-SE son paralelos a la dirección de flujo del acuífero por lo que su papel es el de canalizar el agua desde la zona de máxima recarga en los Riscos de Juel hasta su descarga en el mar. Mientras que por otro las familias con direcciones N-S y NE-SO, perpendiculares a la dirección de flujo, actúan como barreras de menor permeabilidad que compartimentan los canales creados por los diques de la familia NO-SE. De esta forma sobreelevan localmente el nivel piezométrico formando una superficie escalonada en vez de continua. Por último, los diques de la familia E-O no influyen en menor medida en el movimiento del agua en el acuífero. Debido a que el límite del acuífero es una brecha volcanoclástica y que la superficie piezométrica se encuentra escalonada, el espesor saturado del acuífero varía espacialmente.

El futuro análisis de los ensayos de bombeo de los sondeos así como de los datos de descarga de la galería de Ipalán, permitirá la obtención de los parámetros hidráulicos de las unidades hidroestratigráficas que conforman el sistema acuífero de Enchereda. Además, el cálculo detallado de un balance de las entradas y salidas de agua permitirán conocer el grado de explotación del acuífero lo que ayudará a una gestión más sostenible del mismo.

\section{AGRADECIMIENTOS}

Agradecemos a Carlos Soler (Dirección General de Aguas de Canarias) el acceso a los datos de los sondeos así como la entrada a la galería de Ipalán así como al Consejo Insular de Aguas de La Gomera. Este trabajo ha sido parcialmente financiado por el proyecto del MEC CGL2006-06290/BTE. A Emilio Custodio y a un revisor anónimo por sus comentarios y aportaciones al texto.

\section{Referencias}

Ancochea, E.; Hernán, F.; Huertas, M.J.; Brändle, J.L. \& Herrera, R. (2006). A new chronostratigraphical and evolutionary model for La Gomera: Implications for the overall evolution of the Canarian Archipelago. Journal of Volcanology and Geothermal Research, 157: 271-293. doi:10.1016/j.jvolgeores.2006.04.001 
Ancochea, E.; Huertas, M.J.; Brändle, J.L.; Hernán, F. \& Herrera, R. (2008). Dike-swarms, key to the reconstruction of major volcanic edifices: The basic dikes of La Gomera (Canary Islands). Journal of Volcanology and Geothermal Research, 173: 207-216. doi:10.1016/j.jvolgeores.2008.01.020

Braojos, J.J.; García, C.; Martínez, M.M.; Navarro, J.M. \& Soler, C. (1996). Hidrología, balance hídrico, recursos disponibles e hidrogeología. En Avance del Plan Hidrológico Insular de La Gomera. Cabildo Insular de La Gomera. (Soler, C.) Cabildo Insular de La Gomera, 133-183.

Bravo, T. (1964). Estudio geológico y petrográfico de la isla de La Gomera. Estudios Geológicos, 20: 1-56.

Cantagrel, J.M.; Cendrero, A.; Fúster, J.M.; Ibarrola, E. \& Jamond, C. (1984). K-Ar Chronology of the Volcanic Eruptions in the Canarian Archipelago: Island of La Gomera. Bulletin of Volcanology, 47: 597-609. doi:10.1007/BF01961229

Cendrero, A. (1971). Estudio geológico y petrológico del Complejo Basal de la isla de La Gomera (Canarias). Estudios Geológicos, 27: 3-73.

Cueto, L.A.; Gómez, J.A.; Balcells, R.; Barrera, J.L.; Pineda, A.; Cerrato, M.; Klein, E.; Ruiz, M.T. \& Brändle, J.L. (2004). Mapa Geológico de España, 1:25.000, hojas $\mathrm{n}^{\circ} 1.097$ I-II, III y IV y 1105 I y IV. IGME, Madrid.

Custodio, E. (1978). Geohidrología de terrenos e islas volcánicas. CEDEX, Madrid, 303 pp.

Custodio, E. (2004). Basics on Hydrogeology of Volcanic Rocks. En: Groundwater Studies. An International guide for hydrogeological investigations. (Kovalevsky, V. S. Kruseman, G. P. \& Rushton, K. R. eds.) IHP- VI, series on groundwater $n^{\circ} 3$, UNESCO, 395-425.

Custodio, E. (2007). Groundwater in volcanic hard rocks. En: Groundwater in fractured rocks. (Krásný, J. \& Sharp J. M. eds.) International Association of Hydrogeologists Selected Papers 9, 95-108.

Custodio, E. \& Cabrera, M.C. (2008). Síntesis de la hidrogeología de las Islas Canarias. Geo-temas, 10: 785-788.

Custodio, E. \& Saenz Oiza, J. (1972). Estudio geohidrológico del Macizo de Famara, Lanzarote. Ministerio de Obras Públicas. Dirección General de Obras Hidráulicas. Las Palmas; Barcelona, 264 pp.

Descloitres, M.; Rit, M.; Robineau, B. \& Courteaud, M. (1997). Electrical structure beneath the eastern collapsed flank of Piton de la Fournaise volcano, Reunion Island: Implications for the quest for groundwater. Water Resources Research, 33(1): 1319. doi:10.1029/96WR02673

Herrera, R. (2008). Volcanoestratigrafía, composición y evolución de los Edificios Volcánicos subaéreos de La Gomera. Tesis Doctoral, Universidad Complutense, $533 \mathrm{pp}$.

Herrera, R.; Huertas, M.J. \& Ancochea, E. (2008). Edades ${ }^{40} \mathrm{Ar}-{ }^{39} \mathrm{Ar}$ del Complejo Basal de La Gomera. Geogaceta, 44: 7-10.

Herrera, C. \& Custodio, E. (2008). Conceptual hydrogeological model of volcanic Easter Island (Chile) after chemical and isotopic surveys. Hydrogeology Journal, 16: 1329-1348. doi:10.1007/s10040-008-0316-Z

Izquierdo, T.; Márquez, A. \& Herrera, R. (2010). El cálculo de la recarga como primer paso para una gestión sostenible de los recursos hídricos subterráneos de un sistema acuífero volcánico. El caso de La Gomera. CONAMA 10. Comunicación Técnica. Madrid.

Join, J.L.; Folio, J.L. \& Robineau, B. (2005). Aquifers and groundwater within active shield volcanoes. Evolution of conceptual models in the Piton de la Fournaise volcano. Journal of Volcanology and Geothermal Research, 147: 187-201.

Lau, L.S. \& Mink, J.F. (2006). Hydrology of the Hawaiian Islands. University of Hawai'i Press. 274 pp.

Márquez, A.; López, I.; Herrera, R.; Martín-González, F.; Izquierdo, T. \& Carreño, F. (2008). Reconstrucción geológica tridimensional del basamento del volcán Teide bajo el Valle de Icod y la Caldera de Las Cañadas (Tenerife, Islas Canarias). Geo-temas, 10: 13051308.

Michon, L. \& Saint-Ange, F. (2008). Morphology of Piton de la Fournaise basaltic shield volcano (La Réunion Island): Characterization and implication in the volcano evolution. Journal of Geophysical Research, 113, doi:10.1029/2005JB004118,

Mink, J.F. \& Sumida, S.T. (1984). Aquifer classification, State of Hawaii. Report no 75. Water Resources Research Center. University of Hawaii at Manoa. 34 pp.

Navarro, J.M. (1974). Estructura geológica de la isla de Tenerife y su influencia sobre la hidrogeología. Simposio Internacional sobre Hidrología de Terrenos Volcánicos. Tomo I. 37-57. Arrecife, Lanzarote.

Navarro, J.M. \& Farrujia, I. (1989). Zonificación hidrogeológica. Documento $n^{\circ} 1$. Aspectos geológicos e hidrogeológicos. Avance del Plan Hidrológico Insular de Tenerife. $145 \mathrm{pp}$.

Navarro, A.; López, J.A.; La Moneda, E.; Lucena. C.; Ruíz, V.; Adánez, S.; Mateo, E.; Arandilla, M.A.; Gutiérrez, S. \& Mohedano, D. (1991). Actualización del inventario de nacientes de la isla de La Gomera (Proyecto, Mapas y Fichas). IGME, Madrid.

Niñerola, S.; Bascones, L. \& Pérez, M. C. (1974). Estudio geológico general de la Isla de Tenerife, aplicado a la hidrogeología. Simposio Internacional sobre Hidrogeología de Terrenos Volcánicos. Tomo I. 59-91. Arrecife - Lanzarote.

d'Ozuville, N.; Ausken, E.; Sorensen, K.,; Violette, S.; de Marsily, G.; Deffontaines, B. \& Merlen, G. (2008). Extensive perched aquifer and structural implications revealed by 3D resistivity mapping in a Galapagos volcano. Earth and Planetary Science Letters, 269, 518522. doi:10.1016/j.epsl.2008.03.011

Paris, R.; Guillou, H.; Carracedo, J.C. \& Pérez Torrado, F.J. (2005). Volcanic and morphological evolution of La Gomera (Canary Islands), based on new $\mathrm{K}-\mathrm{Ar}$ ages and magnetic stratigraphy: implications for oceanic island evolution. Journal of the Geological Society, London, 162, 501-512. doi:10.1144/0016764904-055

Porras, J.; Gómez, J.; Martín, G.; Lázarao, L.; Olmedo, R.; Fernández, L.; Santana, L. \& Rosa, A. (1985). Estu- 
dio Hidrogeológico General de la isla de La Gomera. Tomo I: Memoria. Tomo II: Planos. Colección Informe. IGME. 170 pp.

Soler, C. (1996) Avance del Plan Hidrológico Insular de La Gomera. Cabildo Insular de La Gomera. 216 pp.

Soler, C.; Horcajada, J. \& Hernández, M. (2002) Plan Hidrológico Insular de La Gomera. Cabildo Insular de La Gomera, 166 pp.

SPA-15 (1975). Estudio científico de los recursos de agua de las Islas Canarias (D. Fernandopullé, S. Sáenz-
Oiza, R. Heras, A. Sahuquillo, \& E. Custodio, eds.) UNESCO-DG Obras Hidráulicas. Las Palmas de Gran Canaria/Madrid. 4 Vols.

Takasaki, K.J. \& Mink, J.F. (1985). Evaluation of major dike-impounded groundwater reservoirs, Island of Оаһи. USGS, Honolulu, 76 pp.

Recibido el 3 de diciembre de 2009 Aceptado el 21 de septiembre de 2010 Publicado online el 3 de febrero de 2011 